\title{
Virtual Reality as a Support Tool for the Treatment of People with Intellectual and Multiple Disabilities: A Systematic Literature Review
}

\author{
Realidade Virtual como Ferramenta de Apoio ao Tratamento de Pessoas com \\ Deficiências Intelectuais e Múltiplas: Uma Revisão Sistemática da Literatura
}

\author{
Rian Dutra da Cunha ${ }^{1}$, Frâncila Weidt Neiva² ${ }^{2}$ Rodrigo Luis de Souza da Silva ${ }^{1 *}$
}

\begin{abstract}
Since the emergence of virtual reality (VR) technologies, many researchers have argued on the benefits of their use for people with intellectual and multiple disabilities. However, up to this date there is not a single study that presents a detailed overview of the state of the art in virtual reality as a support tool for the treatment of people with intellectual and multiple disabilities, as well as Autism and Down Syndrome. The aim of this study is to provide a detailed overview of the state of the art in the virtual reality area focusing on people with multiple disabilities, that encompasses intellectual and physical disabilities. There is still no consensus on the effectiveness of VR-based treatments. Virtual reality can offer rich environment and features, but most of the researches focuses only in the experience to be inside a virtual place without taking advantage of what benefits VR provide us. Furthermore, most of our selected studies used non-immersive VR and AR. Thus, immersive VR is an open field with many opportunities to be explored. We believe VR has great potential to be effective in the treatment of people with intellectual and multiple disabilities.
\end{abstract}

Keywords: virtual reality — augmented reality — intellectual disability — multiple disability

Resumo: Desde o surgimento das tecnologias de realidade virtual (RV), muitos pesquisadores argumentaram sobre os benefícios de seu uso para pessoas com deficiências intelectuais e múltiplas. No entanto, até a presente data, não há um único estudo que apresenta uma visão geral detalhada do estado da arte da realidade virtual como uma ferramenta de apoio ao tratamento de pessoas com deficiências intelectuais e múltiplas, bem como autismo e síndrome de Down. O objetivo deste estudo é fornecer uma visão geral detalhada do estado da arte na área da realidade virtual focada em pessoas com múltiplas incapacidades, que englobe deficiências físicas e intelectuais. Os métodos baseados em realidade virtual têm benefícios potenciais para o tratamento de deficiências intelectuais e múltiplas, no entanto, existem algumas carências neste campo de pesquisa. Ainda não há consenso sobre a eficácia dos tratamentos baseados em RV. A realidade virtual pode proporcionar um ambiente e recursos enriquecidos, mas a maioria das pesquisas concentra-se apenas na experiência de estar imerso em um ambiente virtual sem aproveitar os benefícios que a RV nos oferece. Além disso, a maioria dos estudos selecionados utilizou RV e RA não imersivas. Assim, a RV imersiva é um campo aberto com muitas oportunidades a serem exploradas. Acreditamos que a RV tem um grande potencial para ser eficaz no tratamento de pessoas com deficiências intelectuais e múltiplas.

Palavras-Chave: realidade virtual — realidade aumentada — deficiência intelectual — deficiência múltipla

${ }^{1}$ Federal University of Juiz de Fora, Brazil

${ }^{1}$ Federal University of Rio de Janeiro, Brazil

*Corresponding author: rodrigoluis@gmail.com

DOI: http://dx.doi.org/10.22456/2175-2745.77994 • Received: 13/11/2017 • Accepted: 26/01/2018

CC BY-NC-ND 4.0 - This work is licensed under a Creative Commons Attribution-NonCommercial-NoDerivatives 4.0 International License.

\section{Introduction}

Different studies in literature states that people with intellectual and multiple disabilities present a particular challenge to the Human-Computer Interaction (HCI) community. These challenges are related to develop design interfaces and ap- plications that are effective to treat those individuals, once it is difficult to deal with motor coordination impairment and different intellectual capabilities. Despite the amount of researches of virtual reality systems for rehabilitation in intellectual and multiple disabilities, this area is constantly 
growing.

The authors in [1] defined people with multiple disabilities as individuals with mental retardation who require pervasive supports and who also possess one or more significant motor or sensory impairments. These physical and intellectual problems result in the presence of two or more serious impairments, such as restriction of movement, sensory disorders, speech disorders, difficulty learning, visual and hearing disorders. Authors in [2] define intellectual and multiple disabilities as a set of disabilities formed by learning disabilities, emotional or behavioral disorders, mental retardation, severe and multiple disabilities, Autism, giftedness, health impairments, physical disabilities, speech and language disorders, hearing loss, blindness and low vision, and traumatic brain injury. For this Systematic Literature Review we covered studies that aimed the following disabilities: learning disabilities, emotional or behavioral disorders, mental retardation, severe and multiple disabilities, Autism, physical disabilities and speech and language disorders, as well as intellectual disabilities. In this research, we considered Autism Spectrum Disorder (ASD) as a type of intellectual and multiple disability. According to [3], individuals with ASD have significant development delays in communication and social interaction, demonstrating extreme aloofness to other people, and may exhibit extensive limitations in many adaptive skills. Thus, their disability fits the definition for severe disabilities and mental retardation, despite this is not true for all kinds of Autism (e.g., Asperger syndrome).

Three-dimensional technologies offer significant opportunities for human-computer interfaces and may benefit areas such as training and simulation [4], including those ones focused on people with multiple disabilities. Virtual reality systems make the user capable to interact with virtual objects and, specially, provides the feeling of being inside a threedimensional environment. Virtual reality may offer plenty of advantages for rehabilitation for intellectual and multiple disabilities, for instance, in the virtual environment (VE), people with disabilities are capable to go wherever they want, even if they have mobility impairments. They can repeat as many tasks as they wish or need, and make mistakes during the tasks without suffering dangerous consequences of their errors [5]. Additionally, virtual environments and objects can be manipulated in ways you just can't do in the real world, offering the freedom to create particular tasks with specific levels of difficulty for each type and degree of disability.

Therefore, the aim of this paper is to report the state of the art in the field of virtual reality as a tool for the treatment of people with intellectual and multiple disabilities by means of a Systematic Literature Review (SLR). Thus, we followed the guidelines proposed by Kitchenham and Charters [6].

This paper is organized in six sections, including the current introduction. Section 2 presents the scenario of virtual reality and intellectual and multiple disabilities. The steps performed in this Systematic Literature Review are described in Section 3. Section 4 presents the analysis of the SRL re- sults and their discussion are reported in Section 5. Lastly, conclusions are presented in Section 6.

\section{Virtual Reality and Intellectual and Mul- tiple Disabilities}

Since computer technologies were adopted in the society, many researches have been conducted to investigate the effectiveness of computer-based treatment of people with disabilities. Early studies, for instance [7, 8], suggested that using interactive computer software could encourage language development in children with disabilities. In 1973, Kenneth Mark Colby presented in [7] a system which consisted of a television-like screen and a typewriter-like keyboard in front of child sits. In the experiment, children could interact pressing the keys and symbols appeared on the screen accompanied by sounds of human voices and common noises. V. BernardOpitz said in [9] that children with Autism is more enthusiastic when working with computers than in a "regular toy situation".

In 1981, authors in [10] reported that computer may be a powerful aid in the process of improving communication skills in handicapped children. Despite these early researches were not specific about virtual reality, it is clear that computerbased methods have potential to support treatment of people with disabilities.

With the advances and popularization of virtual reality technology, in 1991, McLellan said in [11] that virtual worlds, unlike real worlds, can be manipulated to make a task easier for the user. In 1995, Melissa Salem Darrow presented in [12] a summary of VR applications developed for people with disabilities, and discussed about the positive predictions for VR as an assistive technology for people with sensory, physical and emotional impairments.

In 1996, Standen and Low in [13] recorded the behavior of 18 teenagers with profound intellectual disabilities over repeated sessions working through a desktop virtual environment aside their teacher. After repeated sessions, the amount of self-directed interaction with the computer increased, and the amount of help they required from their teacher decreased.

Authors in [14] said virtual environments are an effective and safe training and educational media for people with learning disabilities and suggested the need to conduct more researches to understand their full potentials. Also, they said that participants in a VR-based experiments can make as many mistakes as they wish without suffering the real or dangerous consequences of their errors, which is substantially important in this line of research. Dorothy Strickland, in [15] recommended using virtual reality in the treatment of people with Autism, which offers the potential to regulate a virtual environment to better match the needs of people with ASD.

In 1998, Latash [16] discussed a different view of VR scenarios, saying that virtual reality may become too safe and too attractive so that the patient can become a computer addict and be reluctant to re-enter the real world. Also, he mentioned 
that his knowledge of the sensory-motor integration was not sufficient, at that time, to suggest which components of sensations were adequate. Thus, VR would need to provide all the sensations associated with a movement which was not realistic when the author investigated that.

Perhaps the greater challenge in virtual reality applied to the treatment of people with intellectual and multiple disabilities is in fact about human beings, therefore it is very difficult, in most cases, to create virtual reality systems and tools that are really effective for the treatment of those individuals. Nevertheless, there is a plethora of researches in this area.

Virtual reality may offer a variety of possibilities within rehabilitation, including the potential to objectively measure behavior in challenging but safe, ecologically valid environments while maintaining experimental control over stimulus delivery and measurement [17]. The virtual reality system presented in [18] was used to teach people with learning disabilities to prepare food. The authors said the VR-based method was more beneficial than real training with workbook.

A virtual reality for vocational rehabilitation system for people with disabilities is presented in [19]. The authors said VR enables safe immersion of potential employees in a range of scenarios they may encounter before in a real job. Authors in [20] argued that VR-based have an important role to play on many therapeutic areas, specially motor rehabilitation ones. Strickland at al [15] stated that virtual reality offers the potential to regulate an artificial computer environment to better match the expectations and needs of individuals with Autism. A virtual reality based game is presented in [21], which combines the flexibility of VR rehabilitation techniques with the enjoyment of video game.

There is a wide range of possibilities regarding the use of virtual reality for treatment and rehabilitation of people with intellectual and multiple disabilities. To the best of our knowledge there is no study in literature that provide a detailed overview of the state of the art in the virtual reality area focusing on people with intellectual and multiple disabilities, and that is the main contribution of this work, which may serve as a basis for future studies, whether in the field of computer science, physiotherapy, pedagogy or other related areas. The following sections describe deeply the selected studies in the current SLR which illustrate this scenario.

\section{Systematic Literature Review}

A Systematic Literature Review is conducted methodically by following a set of guidelines to collect and analyze all available evidence about a specific question in an unbiased and repeatable manner [6]. To start the process, we defined the protocol that was designed and pilot tested by the first author (student) and reviewed by the second author (supervisor). We describe below steps performed during this SLR.

\subsection{Research questions}

The following research questions were framed to guide the SLR:

- Question 1: What disabilities were treated using virtual reality?

- Question 2: What methods were used in the experiments?

- Question 3: Was virtual reality effective in the treatment?

Based on the research questions, we take into account the PICOC method proposed by Petticrew and Roberts [22] to define our scope:

Population (P): Virtual reality applications which were used for supporting treatments of people with intellectual and multiple disabilities, either autism, motor disabilities and down syndrome. Intervention (I): Virtual reality for health. Comparison (C): Comparison between people with intellectual and multiple disabilities using virtual reality system that supports their treatment with people with intellectual and multiple disabilities who do not use virtual reality. Outcomes (O): Accuracy of improvement of people with intellectual and multiple disabilities. Context(C): People with intellectual and multiple disabilities.

\subsection{Search strategy}

A search strategy starts with the identification of major key terms from PICOC and their synonyms and alternatives. Theses terms are used to form a query string that is used to derive the rest of the search process.

\subsubsection{Query string}

The formation of a query string is an iterative process. Initially, we followed the SLR guidelines [6] to create an initial string using Boolean OR/AND operators (OR is used to incorporate all synonyms and alternate spellings of each term and then theses terms are joined together to form one string). We piloted the initial string on the search engines IEEE Xplore, Scopus, Science Direct and Web of Science using keywords related to this line of research. The keywords used at the first search in virtual reality as support tool for the treatment of people with intellectual and multiple disabilities were: Virtual Reality, Mixed Reality, Down Syndrome, Autis* (autism, autist), Intellectual Disability, Treatment, Virtual Reality Treatment, Virtual Reality Game, Virtual Reality Therapy, Motor Coordination Treatment, Motor Coordination Game, Motor Rehabilitation, Virtual Environment.

\subsubsection{Primary and secondary search strategies}

As part of the primary search strategy, search strings were applied on different databases to fetch the primary studies. Databases, search results, before and after removing duplicates, are listed in Table 1. A master library was formed 
Table 1. Search Results of the primary search strategy

\begin{tabular}{|l|l|l|}
\hline Database & $\begin{array}{l}\text { Before removing } \\
\text { Duplicates }\end{array}$ & $\begin{array}{l}\text { After removing } \\
\text { Duplicates }\end{array}$ \\
\hline IEEE Xplore & 227 & 227 \\
\hline Scopus & 560 & 417 \\
\hline Science Direct & 149 & 149 \\
\hline Web of Science & 513 & 365 \\
\hline Total & $\mathbf{1 4 4 9}$ & 1158 \\
\hline
\end{tabular}

wherein results from all databases were merged and duplicates were removed. At the end, after removal of duplicates, we ended up with 1158 candidates for the primary studies.

Due to the fact virtual reality is a multidisciplinary area, the database we used cover virtual reality conferences but also health conferences and journal of developmental disorders, as well as a few other conferences and journals, thus providing a comprehensive coverage of this SLR's topic. We also ensured that these databases would index all the venues where known primary studies in our topic had been published.

The secondary search was performed in the next phase by going through references of all the primary studies retrieved in the first phase.

\subsection{Study selection criteria}

Inclusion and exclusion criteria were defined in the light of the SLR objectives and research questions.

\subsubsection{Study inclusion criteria}

It was decided that studies that:

a. Are related to Multiple Disabilities or Intellectual Disabilities or Down syndrome or Autism AND

b. Use Virtual Reality or Augmented Reality as the main tool in the experiments AND

c. Have the treatment or stimulation of the fine motor skills or logical reasoning as goal

Will be included as primary studies.

\subsubsection{Study exclusion criteria}

It was decided that studies that:

a. Are not related to Multiple Disabilities or Intellectual Disabilities or Autism or Down Syndrome OR

b. Do not use Virtual Reality or Augmented Reality as the main tool in the experiments OR

c. Do not have the treatment or stimulation of the fine motor skills or logical reasoning as goal

d. Are short paper (less than five pages)

Will be excluded.
Table 2. Title and Abstract level screening.

\begin{tabular}{|l|l|l|}
\hline Database & Selected & Excluded \\
\hline IEEE Xplore & 63 & 164 \\
\hline Scopus & 53 & 364 \\
\hline Science Direct & 21 & 128 \\
\hline Web of Science & 45 & 320 \\
\hline Total & $\mathbf{1 8 2}$ & 976 \\
\hline
\end{tabular}

\subsection{Study selection process}

The study selection process was performed in two phases, as follows:

a. Title and Abstract level screening: In the first phase, the inclusion/exclusion criteria was applied to the title and abstracts of all candidate primary studies identified by applying search strategy. The result is shown in Table 2.

b. Introduction and Conclusion level screening: A second phase was conducted considering introduction and conclusion of the previously selected papers. The result is shown in Table 3.

Table 3. Introduction and Conclusion level screening.

\begin{tabular}{|l|l|l|}
\hline Database & Selected & Excluded \\
\hline IEEE Xplore & 21 & 42 \\
\hline Scopus & 17 & 36 \\
\hline Science Direct & 10 & 11 \\
\hline Web of Science & 16 & 29 \\
\hline Total & $\mathbf{6 4}$ & 118 \\
\hline
\end{tabular}

\subsection{Quality assessment (QA)}

The studies quality assessment checklist was designed based on the checklist suggestion provided in [6]. Four questions in the QA checklist were answered using a three-point scale: Yes ( 2 point), No ( 0 point) and Partial (1 point). Two questions were boolean: Yes (1 point), No (0 point). Each study could obtain 0 to 10 points. In order to select papers with high adherence with this SLR goals, only papers which had 7 points or more were included, i.e., if a study scored less than 7 it was removed from our final list of primary studies. The result is shown in Table 4 . The scores were assigned after a full reading of the articles and are presented in Table 5, which shows only the score for selected papers. The selection criteria are as follows with the respective point scale. In Table 5, the 28 selected papers were identified using a code starting from A1 to A28. The references to the selected papers can be accessed in Appendix section.

a. Is the research aim clearly specified? (0-2)

b. Are the methods clearly described and justified? (0-2)

c. Did the researchers do experiments with people with some kind of disability? (0-1) 
Table 4. Quality Assessment result

\begin{tabular}{|l|l|l|}
\hline Database & Selected & Excluded \\
\hline IEEE Xplore & 6 & 15 \\
\hline Scopus & 5 & 12 \\
\hline Science Direct & 5 & 5 \\
\hline Web of Science & 12 & 4 \\
\hline Total & $\mathbf{2 8}$ & 36 \\
\hline
\end{tabular}

Table 5. Articles analyzed on third phase

\begin{tabular}{|c|c|c|c|c|c|c|c|}
\hline Article & Qa & $\mathrm{Qb}$ & Qc & $\mathrm{Qd}$ & $\mathrm{Qe}$ & Qf & Total \\
\hline [A2] & 2 & 2 & 1 & 2 & 1 & 2 & 10 \\
\hline [A5] & 2 & 1 & 1 & 2 & 1 & 1 & 8 \\
\hline [A16] & 1 & 1 & 1 & 2 & 1 & 1 & 7 \\
\hline [A18] & 2 & 0 & 1 & 2 & 1 & 1 & 7 \\
\hline [A6] & 1 & 2 & 1 & 1 & 1 & 1 & 7 \\
\hline [A22] & 2 & 2 & 1 & 2 & 1 & 2 & 10 \\
\hline [A21] & 2 & 2 & 1 & 2 & 1 & 2 & 10 \\
\hline [A4] & 2 & 2 & 1 & 2 & 1 & 2 & 10 \\
\hline [A17] & 2 & 2 & 1 & 2 & 1 & 2 & 10 \\
\hline [A24] & 2 & 2 & 1 & 0 & 1 & 1 & 7 \\
\hline [A26] & 2 & 2 & 1 & 2 & 1 & 2 & 10 \\
\hline [A27] & 2 & 2 & 1 & 2 & 1 & 2 & 10 \\
\hline [A7] & 2 & 2 & 1 & 2 & 1 & 1 & 9 \\
\hline [A19] & 1 & 1 & 1 & 2 & 1 & 1 & 7 \\
\hline [A11] & 2 & 2 & 1 & 1 & 1 & 2 & 9 \\
\hline [A8] & 2 & 2 & 1 & 2 & 1 & 2 & 10 \\
\hline [A25] & 1 & 2 & 1 & 2 & 1 & 2 & 9 \\
\hline [A3] & 2 & 2 & 1 & 2 & 1 & 2 & 10 \\
\hline [A10] & 2 & 2 & 1 & 2 & 1 & 2 & 10 \\
\hline [A28] & 2 & 2 & 1 & 2 & 1 & 1 & 9 \\
\hline [A15] & 2 & 2 & 1 & 2 & 1 & 2 & 10 \\
\hline [A13] & 2 & 2 & 1 & 2 & 1 & 2 & 10 \\
\hline [A23] & 2 & 2 & 1 & 2 & 1 & 2 & 10 \\
\hline [A14] & 2 & 2 & 1 & 1 & 1 & 2 & 9 \\
\hline [A1] & 2 & 1 & 1 & 2 & 1 & 2 & 9 \\
\hline [A20] & 2 & 2 & 1 & 2 & 2 & 2 & 11 \\
\hline [A12] & 2 & 2 & 1 & 1 & 1 & 1 & 8 \\
\hline [A9] & 2 & 2 & 1 & 1 & 2 & 1 & 9 \\
\hline
\end{tabular}

d. Are the results presented clearly and reliably? (0-2)

e. Are the results based on the experiments? (0-1)

f. The conclusions are well-founded? (0-2)

\subsection{Data extraction and synthesis strategies}

A data extraction form was designed which, besides having general fields (year, conference, author etc.), contained fields corresponding to each research question (e.g., disabilities that were treated, methods used, techniques used to measure the results etc). Data extraction and quality assessment were performed by one of the authors and revised by another one. The extracted data were then synthesized to answer each of the research questions.

\section{Analysis of results}

In this section we present and analyze the results in this SLR, in order to discuss the evidences of the 28 studies that answered the three research questions.

The database which had higher representation was Web of Science, with 12 studies included. Then, 6 studies were from IEEE, 5 from Science Direct and 5 from Scopus. The selected studies are described in two types of publications: conferences and journals. The most common type of publication we identified in this SLR is journal, with $82.14 \%$ (23/28), and then conferences, with $17.86 \%(5 / 28)$. Tables 6 and 7 show the journals and conferences which the studies were selected from.

Table 6. Journals in this SLR

\begin{tabular}{|l|c|}
\hline Journal & Studies \\
\hline Computers \& Education & 1 \\
\hline Computers in Human Behavior & 1 \\
\hline Educational Technology \& Society & 1 \\
\hline Electronic Journal of e-Learning (EJEL) & 1 \\
\hline Games for Health Journal & 3 \\
\hline $\begin{array}{l}\text { IEEE Transactions on Neural Systems } \\
\text { and Rehabilitation Engineering }\end{array}$ & 1 \\
\hline $\begin{array}{l}\text { IEEE Transactions on Visualization } \\
\text { and Computer Graphics }\end{array}$ & 1 \\
\hline Interactive Learning Environments & 1 \\
\hline International Journal of Child-Computer Interaction & 5 \\
\hline Journal of Autism and Developmental Disorders & 1 \\
\hline Journal of Neuroscience Methods & 1 \\
\hline Presence: Teleoperators and Virtual Environments & 1 \\
\hline Research in Developmental Disabilities & 1 \\
\hline The International Journal of Research and Practice & 1 \\
\hline The Journal of Educational Research & 1 \\
\hline The Journal of Special Education & 1 \\
\hline The Scientific World Journal & \\
\hline
\end{tabular}

Table 7. Conferences in this SLR

\begin{tabular}{|l|c|}
\hline Conference & Studies \\
\hline $\begin{array}{l}\text { International Conference of Design, } \\
\text { User Experience, and Usability }\end{array}$ & 1 \\
\hline $\begin{array}{l}\text { International Conference on Control, Automation, } \\
\text { Robotics and Embedded Systems (CARE) }\end{array}$ & 1 \\
\hline $\begin{array}{l}\text { International Conference on Enterprise } \\
\text { Information Systems (ICEIS) }\end{array}$ & 1 \\
\hline $\begin{array}{l}\text { International Conference on Physiological } \\
\text { Computing Systems }\end{array}$ & 1 \\
\hline $\begin{array}{l}\text { Information Technology in Medicine } \\
\text { and Education (ITME) }\end{array}$ & 1 \\
\hline
\end{tabular}




\subsection{RQ1: What disabilities were treated using vir- tual reality?}

Twenty six out of the 28 selected studies, investigated the use of virtual reality and augmented reality technologies in the treatment of people with Autism Spectrum Disorders (ASD), covering aspects such as social interactions and verbal and non-verbal communication [A2, A5, A16, A18, A6, A22, A4, A17, A24, A26, A7, A19, A11, A8, A25, A3, A10, A28, A15, A13, A23, A14, A1, A20, A12, A9]. Two studies examined the feasibility of using VR and AR as means to support the treatment of People with Intellectual Disabilities [A21, A27]. Among these studies, $64.29 \%$ of them focus on children, while the other part focus on adults with disabilities, as well as adolescents. Some of the studies aims to improve characteristics of the people with Autism and Intellectual Disabilities (IDD), such as: social interactions, facial expression recognition and physical fitness. A few studies investigate the impact of VR and AR in the treatment and other focus on improving specific abilities of people with ASD and IDD (Figure 1).

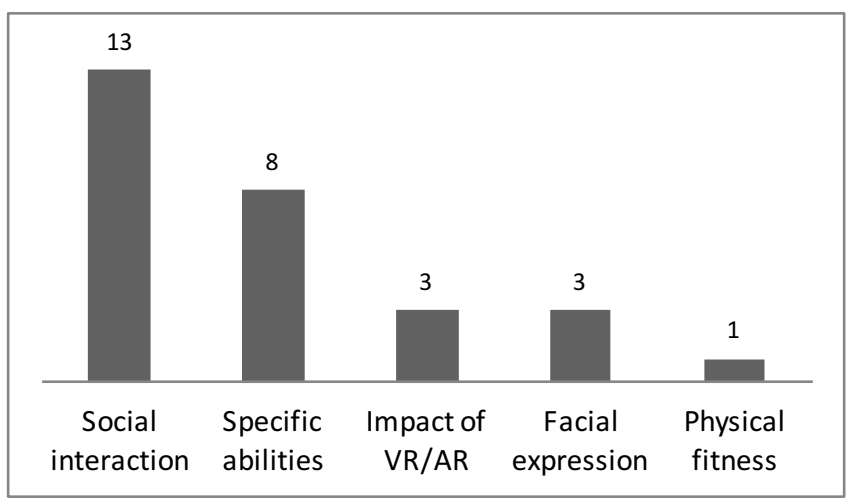

Figure 1. Overview of the studies clustered by main objective

The studies presented in [A16, A22, A17] showed that children with Autism are characterized by deficits in socialization, communication and interaction, and the studies [A5, A16, A18, A22, A17, A7, A19, A11, A8, A10, A15, A20, A9] explore the potential of VR and AR technologies to encourage social interaction among people with ASD. Particularly, the study [A5] shows the capability of VR systems to improve, among other social tasks, the nonverbal communication of children with ASD.

The studies [A6, A3, A12] used VR and AR technologies to improve the recognition and understanding of the emotions in facial expressions in social interaction between people with and without ASD. In [A6] the authors focused specially on the 6 basic emotions in the 6 basic facial expressions: anger, fear, disgust, happiness, sadness and surprise. In the system presented in [A3] the authors examined performance and process differences between adolescents with and without ASD on tasks of facial emotion recognition. The authors in [A12] developed a game that aims to help people with Autism collaborate with other people, teaching them how to interpret complex emotions, thus, improving their socialcommunicative skills.
Only the study [A21] aimed to test the effectiveness of a VR system to improve the physical fitness of people with Intellectual and Developmental Disabilities (IDD). The authors said that most individuals with IDD tend to avoid participation in such activities, showing a lack of physical fitness.

Three of the studies explored the efficiency of VR systems in the treatment of people with ASD and IDD [A26, A27, A25]. Dorothy Strickland in [A26] investigates the potential of VR as a tool for teaching people with ASD, while in [A27, A25] the authors explore the efficacy and feasibility of coaching in virtual environments for improve social skills performance, such as a job interview.

The other studies are all related to Autism, but in each one of them the authors focused on testing the technologies to improve specific abilities of the participants. In [A2, A13] the authors present a system aimed to promote a "pretend play" for children with ASD, which is related to imagination and cognition abilities. The assistive VR-based driving system presented in [A4] was developed to improve driving skill of teenagers with ASD. The authors also care about affective states such as engagement, enjoyment, frustration and boredom. The authors in [A24] say the children with ASD face difficulties in understanding what others think and feel, so they aim to design a learning environment for them. The studies [A28, A23] evaluated intervention of VR system to improve cognitive aspects in children with ASD. The study [A14] aims to enable people with Down Syndrome to be more independent, training. Finally, the [A1] study aims to improve the attention of people with Autism.

\subsection{RQ2: What methods were used in the experi- ments?}

The vast majority of the selected studies use non-immersive virtual reality system in the experiments. Only the [A26, A1, A20] studies investigated the potential of the immersive VR to provide a safer and customized learning environment for children with Autism. Furthermore, in the context of this Systematic Literature Review, we consider augmented reality as part of this research. Over the 28 selected studies, only the studies [A2, A6, A8] investigated the use of augmented reality in the treatment of people with ASD.

The studies [A5, A6, A24, A26, A11, A8, A3, A13, A14, A1] use VR and AR to assist children to recognize geometric shapes, objects, gestures, facial expressions and to discriminate pictures as well. In another context, the studies [A16, A18, A17, A24, A27, A19, A25, A15, A20, A9] investigate the feasibility of an engaging VR social training intervention focused on enhancing social skills. On the other hand, almost all selected studies introduce some gamebased task or serious games features, such as the studies [A5, A6, A19, A25, A3, A13]. However, the studies [A22, A4, A21, A24, A7, A15, A12, A9] fit better in the game category, because they use game in fact or presented some game developed for the experiments.

Figure 2 shows the methods categories that clusterizes the 
selected papers according to their main focus, where "Other" are non-categorized studies in this context. The following sections describe briefly which methods were used in the selected studies.

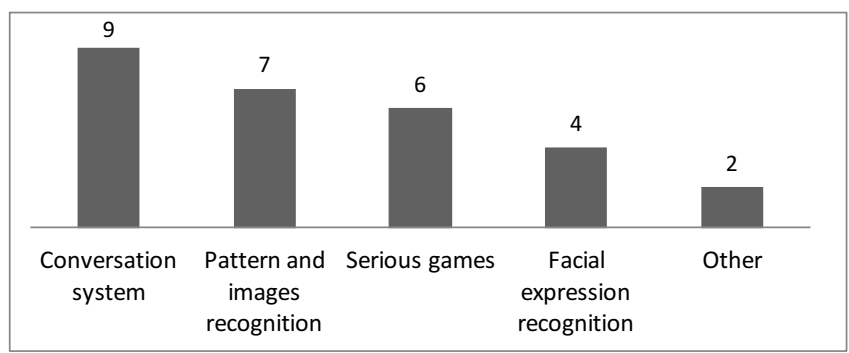

Figure 2. Overview of the studies clustered by categories

\subsubsection{Conversation system related studies}

In [A16, A18, A17] it is presented a VR-based social conversation system. However, in [A18] the system has a Gazesensitive adaptive response technology that uses eye-tracking techniques, which is capable of identifying and quantifying children's engagement level by measuring viewing patterns and changes in eye physiological responses. Both follows a similar procedure. At first step, after the experimenter briefed the participant about the study and demonstrated the experimental setup, sensors were placed on the child's finger. After that, an avatar narrated a story, when it exhibited emotions depending on the content of the story. During this step, participant interact with the virtual character. At the end, the system provided feedback, showing the participant's performance score. Likewise, in [A19] the authors presented a novel physiologically responsive VR-base system for conversation skills between people with ASD. They used several standardized tests for enrolling the participants with Autism, which are commonly used in special education to evaluate communication, social interaction, verbal ability and other features of the individuals depending on the type of test. For the study, the authors developed twenty-four VR-based social tasks with avatars narrating personal stories to the participants.

A simulated job interview VR-based system for improving job interview skills among individuals with Autism was presented in [A25]. Participants had to start a job interview in a non-immersive virtual environment and should answer questions made by the virtual interviewer. According to the answers, the program scored from 0 to 100 , referred to eight domains: negotiation skills, dependable, teamwork, sharing things in a positive way, honesty, sounding interested in the position, acting professionally, and establishing empathy rapport with the interviewer. Similarly, in [A27] the authors explore the efficacy of role-playing and coaching in virtual environments for the improvement of social skills in job interview performance. Five People with Intellectual Disabilities were submitted in an assessment that was done in a laboratory that combines a physical space with simulated people. The assessment consisted in a eleven-question interview. At the end, the score was showed.
The work presented in [A15] also investigated the feasibility of an engaging VR Social Cognition Training (VR-SCT) intervention focused on enhancing social skills. To do that, authors selected eight people with ASD to use Second Life, a three-dimensional virtual world software, where there were different contexts, such as meeting new people, dealing with a roommate conflict, negotiating financial decisions and interviewing for a job. Afterwards, a battery of social cognition measures was selected to assess performance before and after the VR-SCT intervention in three areas of social skills and cognition: verbal and non-verbal emotion recognition, Theory of Mind, and conversation skills.

The study [A20] presented an immersive VR system that trains and improves the emotional skills of children with Austism. The system introduces the participants to 10 social situations (e.g., going to a birthday party, playing soccer) and the users must interact with an individual in the virtual environment, allowing them to learn the appropriate behavior and apply it in different occasions.

\subsubsection{Pattern and images recognition related studies}

The virtual dolphinarium presented in [A5] allows children with ASD to act as dolphin trainers, focusing on improving their functional development learning and behavior. After initial tests done to determine their intellectual levels in terms of Nonverbal Intelligence Quotient (NIQ), the children entered in an immersive room, where they could start the experiments in front of a big curved screen spanning a $320^{\circ}$. Six tasks were assigned to them: identifying parts of a dolphin, identifying shapes traced on palm, geometric shape copying, copy-drawing of a dolphin, dolphin maze, name writing and sentence copying. After all, participants watched a short tutorial on how to interact with virtual dolphins using hand gestures.

Authors in [A24] present a virtual environment system for face-to-face interviews that uses picture exchange communication system (PECS) methodology for data collection. The authors present PECS as a communication method that does not require speech that has been widely used in various researches pertaining to children with Autism. They say the PECS methodology was used to select the best fit objects related to the chosen environment. Thus, in the experiments, participants were asked to give the correct picture to a pattern of objects or specimens.

The [A8] study investigates the use of AR to assist children to recognize pictures. Thus, it provides a tool to assist interventions performed by therapists and support for parents to join in the child's intervention. In the sessions, therapists showed the participants AR cards which activated 3D objects through a monitor and an AR system. The children had to recognize the objects and sounds.

Dorothy Strickland in 1996 presented a VR-based learning tool in [A26] aimed to efforts at treatment and intervention for children with Autism. Two autistic children were selected for the experiments, which consisted of over 40 virtual exposures during a 6-week period. In the initial test, the child had to 
recognize a common object (e.g., car) in an immersive virtual reality three-dimensional world.

The authors in [A13] examines the effectiveness of using a virtual reality tool for teaching understanding of "pretend play" of children with Autism. The methodology presented consisted in selecting two individuals with ASD and give them a touch screen device, so they could explore a virtual supermarket, where the children had to buy things by following a list. After this stage, a video was showed for every object, indicating how it is used. The subsequent stage is similar and the participant should watch a video that shows a child playing with the current object. There were two other stages called "Imaginary Play" and "Creative Use", and they also focus on "pretend play". For collecting data, they used specific questionnaires and a clinical history was obtained through interviews with parents and professionals.

The [A14] study aims to enhance the autonomy of people with Autism, training them for handling money using a screen of an application to a palpable table. The interactive table combines the size of a table with $3 \mathrm{D}$ hand position recognition. Authors in [A1] presented a VR-based Brain Computer Interface paradigm using social cues to direct the focus of attention of people with Autism.

\subsubsection{Serious games related studies}

A serious game is presented in [A22]. The authors propose a two-player block challenge task where two children have to communicate verbally and collaborate with each other to complete the game successfully, thus teaching the individuals to work together. In the game, after the children select a block, it appears in the middle of the room with incorrect orientation relative to the two participants. Then, the children needed to collaboratively rotate the block into its correct orientation. In the experiments, there were three thirty-minutes sessions.

Another serious game is showed in the [A4] study, where the authors developed a VR-based driving environment for skill training of teenagers with Autism. During the experiments, physiological signals were collected from the participants to detect affective states: engagement, enjoyment, frustration and boredom. There were six sixty-minutes sessions in several days. First, the teenagers watched an instructional video and then practiced during three minutes. After that, the assignment began. Through the task, participants tried to follow the navigation system and tried to obey traffic rules. Disobeying any traffic rules or four failures caused the game over.

In [A21, A7] the authors conducted experiments using Active Video game Play which included game-like exercises. Both investigated the effectiveness of the use of games in physical activities. In [A21] the experiments were done with People with Intellectual Disabilities and in [A7], with children with Autism. Besides that, the [A7] study also investigated the effects on social behavior for children with ASD. Forty five participants were selected in [A21]. In the sessions, they stood or sat in a demarcated area viewing themselves on a large video screen that displayed simulated functional tasks, such as catching virtual balls. The user's movements controlled the interaction with virtual objects within the virtual environments. During the tasks, they were encouraged to use all body parts and a therapist guided them verbally and physically while they used the VE. In [A7] the authors compared active videogaming with sedentary gaming for children with Autism. In the experiments, hand-held controlled games and Kinect games were used.

The game developed by authors in [A12] uses Kinect to help people with Autism collaborate with others, improving the social-communicative skills of them. Participants can play the game with gestures. During the game, they should construct the body of the figure and choose the correct emotion for the face of the character according to the scene. In [A9], by using an OpenSim-based virtual world, the authors conducted qualitative analyses with the data collected from an exploratory case study of a VR-based collaborative design tested with children with Autism. The design required participants to work in partnership to build a virtual neighborhood which was devastated by a tsunami earthquake.

\subsubsection{Facial expression recognition related studies}

The authors in [A6] presented an augmented reality-based video-modeling storybook which focus on the improvement of the perceptions of facial expression and emotions of the children. Six people were recruited for the experiments, where they were asked to open a storybook which has frozen images captured from video in its pages. Each picture was about nonverbal cues (e.g., situations, body movements, facial expressions). Using a tablet with an AR system, children could watch short videos displayed in a virtual layer overlaid in the storybook. Afterwards, a therapist asked the children to select an appropriate emotion that corresponded to the scenes (e.g., anger, fear, sadness).

The [A11, A10] studies are also about facial expression recognition, which presents a method containing three social interaction tasks: facial expression and gestures recognition of a virtual communication partner, responding and maintaining interactions at a virtual school cafeteria, and maintaining interactions at a birthday party. In the program, each child went through over 6 to 9 one-hour sessions during 4 to 5 weeks. During the procedure, data were collected in the VR environment.

The authors in [A3] selected two groups of ten people with Autism. In a room with a desktop monitor and an eye tracker, they were submitted to the experiments. A few 3D avatars were placed in front of the participants, each one with specific facial expressions and different emotion intensity levels. So, participants should choose the correct facial expression through a menu. Thus, authors were able to examine performance between adolescents with and without ASD on tasks of facial emotion recognition.

\subsubsection{Not categorized studies}

In the augmented reality system presented in [A2] the authors aimed to promote "pretend play" for children with Autism. 
To do that, the system simulated a mirror in front of the child using camera, monitor and the child's inverted captured image. A pilot study was conducted to test whether normally developed children could interact successfully with an AR system. In the experiments, children used blocks with AR markers which displayed virtual toys over them. Thus, they were asked to show how he or she could play with the block as a car, train or airplane, for instance. Afterwards, the authors analyzed the participant's play behavior based on the video footage recorded during the tasks.

The [A28] study evaluated a novel intervention that combined VR with traditional cognitive rehabilitation methods to address impairments in contextual processing of objects in children with ASD. Several tasks were done in relation to the positioning of the objects, for instance whether a object is in the same direction of another one.

\subsubsection{Devices and techniques used to create VR and AR}

Among the selected studies, only [A26] used immersive virtual reality in the experiments. Because of this fact, its settings are described in details. The authors used a ProVision 100 fully integrated VR system provided by DIVISION Inc., which contained pixel-plane hardware for fast image calculation, texture mapping of objects, and perspective correction at up to 997 million pixels/sec with 24 bit color. The tracker was a Polhemus Fastrak ${ }^{\mathrm{TM}}$, the headset was the Divisor made by DIVISION Inc. with a field of view of $41^{\circ}$ vertically and $105^{\circ}$ horizontally, with $75^{\circ}$ per eye, and the resolution was 345 horizontal by 259 vertical pixels.

Microsoft Kinect was used in [A5, A7]. In [A5], Kinect was needed to capture the participant's movements and gestures, as well as in [A7], where it is used by the Microsoft Xbox games. Only in [A6] a tablet computer was required to create augmented reality. In [A21] a specific setup was presented. The authors chose to use the Gesture Xtreme (GX) Virtual Gaming System, which is a virtual multiplayer gaming system that consists of processor, hardware, video camera and GestureXtreme software. Also, the GX system provides a few virtual games. In [A27] the setting was TLE TeachLivE ${ }^{\mathrm{TM}}$ virtual classroom laboratory with a large projection screen. Beside these, the studies [A2, A16, A18, A22, A4, A17, A24, A19, A11, A8, A25, A3, A10, A28, A15, A13, A23] used flat desktop monitors or laptops to create virtual reality or augmented reality.

\subsubsection{Evaluation and data analysis}

Overall, the articles used more than one way to evaluate their methods. The studies [A5, A16, A18, A6, A22, A27, A19, A25, A3, A28, A15, A23, A20] obtained specific scores in the performed tasks during the experiments, thus evaluating the participants' performance according to the proposed rules in each research. Figure 3 illustrates this scenario.

In [A22, A21, A17, A24, A3, A28, A13, A23, A1, A9] the authors analyzed data collected from the experiments. In [A22] the analysis focused on three main aspects of the interactions, such as interaction movement, peer-peer communi-

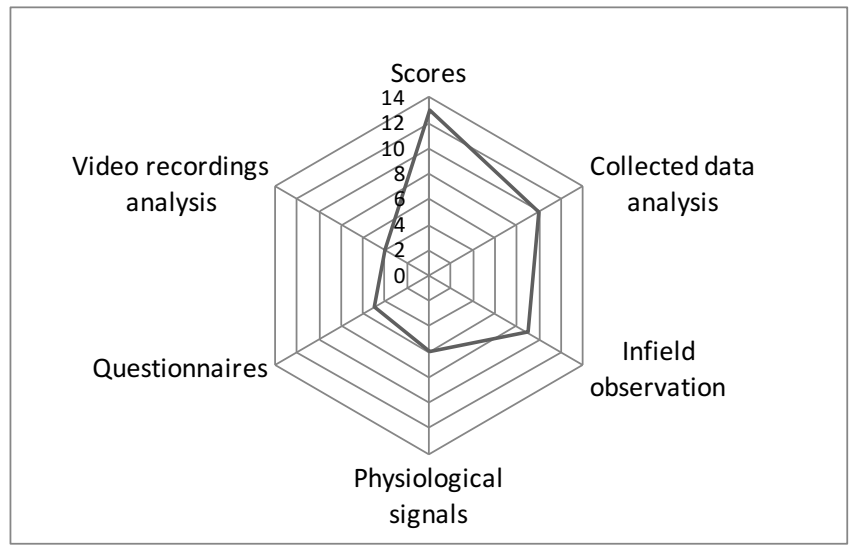

Figure 3. Studies clustered by evaluation and data analysis

cation and teacher facilitation. The authors in [A3] examined the participant performance using metrics such as accuracy, response latency and ratings of response confidence and used a Analysis of variance (ANOVA) approach which included intensity as a factor for examine each variable. In [A13], data were also collected before the sessions began, by specific questionnaires and a clinical history obtained through interviews with parents and professionals.

In [A6, A21, A17, A7, A8, A10, A12, A14], besides their evaluation material, an infield observation was needed, specially in [A26] where there was only infield observation and no more ways to evaluate the experiments. Among these researches, except [A7, A10], the sessions were conducted by therapists and the participants' performance could be monitored by the professionals.

The authors in [A16, A18, A21, A4, A17, A19] used physiology based markers for predicting the participants' affective states. Thus, they investigated the feasibility of using the physiological markers as affective cues which in turn can make the Human Computer Interaction more effective and meaningful. In [A16], physiological signals was used as marker of the participants' affective state such as anxiety, extracting the average heart rage of the individuals while participating in the VR based tasks. Also, they measured the participants' surface body temperature during the tasks. The [A21, A4] studies also monitored changes in heart rate. The systems presented in [A18, A4, A19] captured eye data of the participants while interacting with the virtual objects and environment using eye tracker, detecting subtle variations in the individuals' eye-physiological features. In [A19], the eye physiological features were related to pupil diameter and blink rate. The system showed in [A17] monitored pulse, skin temperature and also used Electrodermal Activity (EDA) sensors which recorded the skin conductivity and could detect the individuals' anxiety level.

Questionnaires were used in [A2, A7, A19, A11, A13] to collect data from the participants. In [A2] the authors used both parent questionnaire and participant questionnaire to collect qualitative feedback to evaluate the emotional quality of the participants' involvement in each condition. In the 
[A19] study a few questionnaires were used for enrolling the participants with Autism, for instance Social Responsiveness Scale (SRS) designed to quantitatively measure the severity of autism-related symptoms. In [A13] there were specific questionnaires for collecting any potentially pertinent data, such as the play techniques used before the study and the attitude towards computers.

The authors in [A2, A11, A8, A10] analyzed participants' behavior based on the video footage recorded during the experiments. Thus, qualitative analysis was conducted with the video recordings of the interaction activities.

\subsection{RQ3: Was virtual reality effective in the treat- ment?}

A few authors in the selected studies talked about the advantages of virtual reality and suggested that VR could be very useful for the treatment of people with intellectual and multiple disabilities, but did not present real results of the experiments. Thus, we considered that virtual reality was effective in the studies where statistical data were presented or the authors discussed about the real results showing the benefits.

Among the selected studies, we considered the studies [A2, A16, A18, A6, A22, A17, A27, A19, A25, A10, A28, A15, A13, A1, A20, A12, A9] presented significant and reliable results. In [A21, A7, A3] the authors said the participants performances were slightly enhanced, so we considered the virtual reality methods were not effective indeed. The authors in [A5, A4, A24, A26, A11, A8, A23, A14] did not present any statistical data or significant conclusion about the effectiveness. Figure 4 shows this scenario.

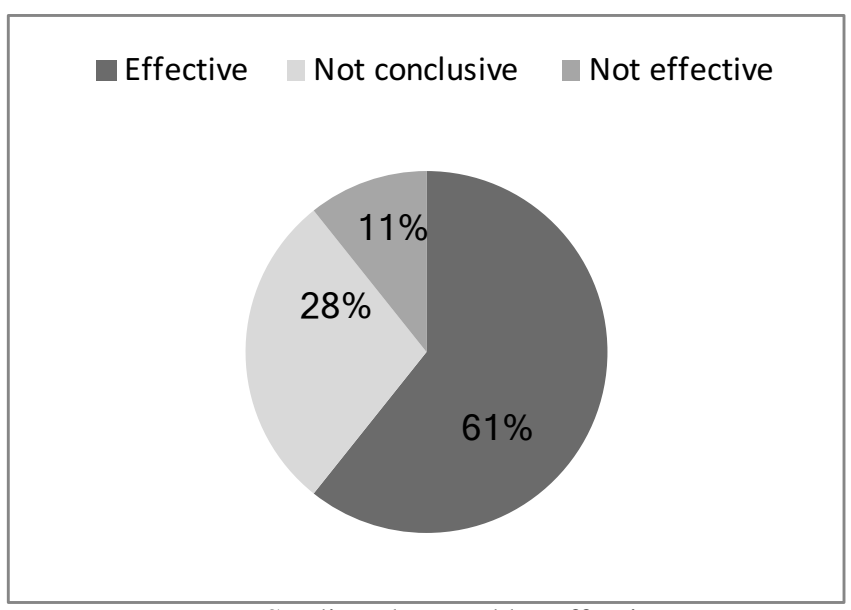

Figure 4. Studies clustered by effectiveness

In [A2, A13] results indicate a positive effect of increased elicited "pretend play" in frequency, duration and relevance with the augmented reality system compared with a noncomputer setup. In [A22] the author suggests the multi-user VR game could be a useful technology-based educational intervention, and presents the results showing a few graphics analyzing the data, indicating the children with ASD made more communicative moves to their partners than the TD (typically developing) children.

In [A16, A18, A17, A19, A10, A15, A20, A9] the studies indicates the potential of the virtual reality system to improve social task performance and to induce variation in participant's physiological markers. In [A16], the authors showed a table demonstrating an improvement in performance score for all participants. The authors in [A18] found an improvement in the viewing pattern in terms of increased FD (fixation duration) of all the individuals while looking toward the face region of the virtual avatar during interaction with ES (engagement-sensitive system), which is a system based on the composite effect of one's viewing pattern, compared to the one with the PS (performance-sensitive system), a system that is based on one's performance metric alone. The authors in [A19] used graphics to show the task progression of VR-base social communication task while interacting with a PS and an ES system for the participants. In [A17] the authors said the system has the potential to use individuals' real-time physiological signals as markers of their anxiety level. In [A15], to assess the efficacy of the VR system, mean difference change scores were analyzed with $95 \%$ confidence intervals. Results found that a social skills training intervention may enhance performance on emotion recognition from faces.

In [A6] a figure was showed with results of the experiments. The authors affirm the augmented reality-base video storybook system proved useful for teaching the pediatric participants with Autism how to recognize the emotions in facial expressions.

Through figures and graphics in [A27, A25] showing the interview scores recorded by participants, an increase in their performance was showed. Thus, the intervention demonstrated to be effective to improve job interview skills in the virtual environment as well as generalization in face-to-face interviews. However, the findings in [A25] suggest that the training is still generalizable to adults with Autism, as they demonstrated significantly improved job interview skills between the baseline and follow-up role-play sessions.

Authors in [A28] presented the percentage accuracy on the virtual reality experiments demonstrated by the participants. All children who participated in the experiments demonstrated statistical improvements in overall contextual processing ability. Nevertheless, as well as most selected studies, the authors said a large-scale study would be needed to evaluate the magnitude of change resulting from the intervention.

In [A20], for data analysis from the psychopedagogy, a qualitative, quantitative and experimental methodology was used, and statistical results were showed, presenting a significant presence of more appropriate emotional behaviors in the immersive environments in comparison with the use of desktop virtual reality applications, according to authors.

The [A5] study did not present any statistical result, thus we consider the study was not conclusive in fact, whether the virtual reality is effective in the treatment of people with intellectual and multiple disabilities, although the authors 
presented advantages and a table containing the participants' scores. The same happens in [A4], where the author said application of advanced intervention that address deficit in driving for people with ASD lacked the ability of detect the affective cues of the participants. They proposed, in the future, a real-time affect recognition system which dynamically shape the driving task to be developed and did not affirm whether the VR was indeed effective in the current research.

The study [A26] concluded about the essence of virtual reality worlds and the sense of presence it is able to create, and the author said more tests would be necessary to determine the effectiveness of the method which uses virtual reality.

The [A11, A23] studies indicated the virtual reality is still in need of further development to support better social skill training, although the authors said the findings should enrich the research area of technology-enhanced special education. In [A8], the children were highly motivated by the usage of augmented reality and the therapist who was presented in the experiments concluded an AR based approach has the potential to present benefits in speech-language therapy. However, they did not show any data or statistical result.

The authors in [A21, A7, A3] concluded that virtual reality was not effective in fact. In [A21], although the VR-based intervention was feasible and suitable for people with intellectual and Developmental Disabilities, their physical fitness was only slightly enhanced. Despite, the authors said the current results are in contrast with the previous ones. Conclusions in [A7] show active video game has inconsistent effects on social behavior for children with Autism. On the other hand, the authors said augmented reality games should be evaluated for potential benefits on socialization and positive affect, but AR was not the focus of this study. The hypotheses in [A3] were partially supported, such group differences emerged when examining response eye gaze, latency and confidence in responses. However, the participants could not identify emotions correctly. No significant difference was found between groups in terms of overall performance accuracy.

\section{Discussion}

From the results obtained in this Systematic Literature Review, it is possible to notice that virtual reality in the context of treatment of people with intellectual and multiple disabilities still needs to be studied deeply, mainly because it is about human beings and hence it is a very complex area, besides VR technologies are still in constant evolution, including the interaction between users and virtual objects and environment, as well as VR devices (e.g., headsets, gloves).

An interesting point to be observed is, despite immersive virtual reality was already available years ago, with the use of headsets for instance, over the 28 selected studies, solely in [A26] study the author investigated the use of VR as tool for teaching people with Autism, although this research is from 1996, while the other studies is up from 2000's.

Perchance, may be due to the fact the immersive virtual reality devices such as headsets and interactive gloves may not be ready to be used the way we expected, specially with people with intellectual disabilities, who have quite difficulty in motor coordination in most cases, or maybe because the affordability of those devices. Affordable devices such as Oculus Rift and Google Cardboard were released in 2013 and 2014, respectively. Nevertheless, the version of Oculus Rifts presented in this year was the development kit, which had low resolution screen (640x800 pixels per eye) and it is still improving. Only in 2016 the virtual reality headset was released officially. Possibly in the next years researches about immersive VR will show up.

Several methodologies have been shown in the selected studies, in an attempt to treat the participants, however we can say there has been no progress regarding the virtual reality technology, both for software and hardware. Overall, the authors used videos played through PCs and tablets [A2, A6, A21, A4, A7, A13], big screens with common video game systems such as Nintendo Wii and Microsoft Kinect [A5, A21, A7, A12], but no specific system or device were developed in the studies to help measure the benefits of the methods applied. In most cases, virtual reality was used only to immerse the participants in a different and virtual environment, but the authors did not investigated all resources that technology can offer regarding the users interactions, such as manipulating virtual objects with their own hands and interfering with the virtual environment in fact.

Almost all the selected studies were about Autism. Among the studies in this SLR, 26 researches aimed to use virtual reality to investigate its benefits on the treatment of people with Autism, and only 2 of the studies [A21, A27] focused the research on people with intellectual disabilities. Thus, there is a huge lack of researches that investigate VR in treatment of other intellectual disabilities, as well as motor coordination disabilities.

Virtual reality can offers us a vast range of resources that may be strongly useful in the treatment of people who have difficulties in motor coordination and logical reasoning. Despite the contributions presented in the researches we described in this SLR are important, in most cases, for the growth and evolution of the virtual reality in this scenario, any of the studies investigated VR-based methods to improve or treat motor coordination, logical reasoning or body balance of people with intellectual and multiple disabilities, for example.

Another aspect to be considered is that virtual reality based methods were effective in the treatment of the participants only in $61 \%$ of the studies. Moreover, $11 \%$ of them were not effective and $28 \%$ were not even conclusive, as described in subsection 4.3, demonstrating an area that is still in evolution and needs to be more clarified.

Furthermore, even when 17 of the 28 selected studies considered the methods presented effective (which are the studies [A2, A16, A18, A6, A22, A17, A27, A19, A25, A10, A28, A15, A13, A1, A20, A12, A9]), overall the experiments were done with a small sample of people with disabilities, in most cases around 5 participants. In [A5], 15 children were 
selected, however it is still a low number of participants to be sure that the VR-based methods were or were not effective in fact.

There is still no consensus on the effectiveness of virtual reality in the treatment of intellectual disabilities, mainly because of the lack of a standard method to measure the improvements of the individuals performance along with the experiments.

Regarding the human beings involvement, to measure the performance of each individual is a complex task, as well as detecting their improvements. Specially when the study attempts to improve the socialization abilities of the participants as well as their communication skills, it is totally dependent on other professionals from other areas such as psychologists and therapists.

Even in some articles the authors presented statistical data, for instance in [A16, A18, A6, A7, A25, A28, A13, A9], in most cases the results are given by the authors' and other area professionals' observation made during the experiments. Although most of the articles indicated the potential and possible benefits of the virtual reality based methods in the treatment of intellectual and multiple disabilities, there aren't strong evidences to assess how reliable are the results and how effective virtual reality is in fact.

\section{Conclusion}

This paper presented a Systematic Literature Review in virtual reality as a supporting tool for the treatment of people with intellectual and multiple disabilities. The primary search found 1163 studies and 28 studies were selected after a systematic process of analysis. An analysis was done from data extracted from these 28 selected studies.

Based on this SLR, it is notable that there are some lacks in this line of research and there is much to be explored regarding the use of VR in the treatment of people with intellectual disabilities. There is still no consensus about the effectiveness and efficiency of VR in this context, even $61 \%$ of the studies considered it was effective.

Twenty six of the selected studies aimed to use VR to support treatment of people with Autism, and only 2 studies focused the research on people with intellectual disabilities. Thus, there is a huge lack of researches that investigate VR in treatment of other intellectual disabilities, as well as motor coordination disabilities. Eleven studies used VR as a medium and did not explore all features virtual reality can offer to the individuals, such as interaction with virtual objects and virtual environment. Another aspect to be considered is that the vast majority of the selected studies did experiments with only a few people with intellectual disabilities, which may return inaccurate results.

Despite the selected studies presented different methods and ways to explore VR in this context, there are still some gaps in this field of research that can be seen as good opportunities for new researches. Over the selected studies, there was no evolution in relation to the virtual reality technology, con- sidering both software and hardware. Most of the researches focused only on the experience and sensation to be in a virtual environment, but did not developed any new tools nor specific system that could support the data analysis and help to measure the benefits of the methods applied during and after the experiments, such as a system to automate the performance evaluation of the participants, nor a game that adapts itself to the individuals performance along the evolution of their treatment, nor a system that presents statistical data of the patients in an automated way.

Another important aspect is that only one over the 28 selected studies explored immersive virtual reality system in the experiments, which is from 1996, thus the immersive VR devices were quite new with low quality. Perhaps, one of the greatest limitation, specially for the older studies, was the VR technology, which is still in evolution and may not be ready to be used the way we expected, specially with people with intellectual disabilities. Another aspect is the affordability of those devices, regarding the price. Only from 2013 lowprice devices were released, such as Google Cardboard. Thus, possibly in the next few years, researches regarding the use of immersive VR will show up.

When it comes to treatments or development of any type of disability, it is crucial to understand we are dealing with human beings, and because of that, each person necessarily is different from each other and so are their needs and impairments. In view of this, it becomes difficult to develop an automatic system or a default method that fits in every kind of person with intellectual and multiple disabilities. Therefore, it is needed to do large-scale researches and experiments to be able to get more accurate results and more effective VR systems.

For those who intends to continue this research or any VR-related researches focused on people with disabilities, it is important to highlight the nature of this field. Virtual reality alone encompasses several different disciplines, and, when it comes to people with disabilities treatment and development, it becomes even more multidisciplinary and dependent on various types of professionals, covering fields like computer science, interaction design, physiotherapy, pedagogy, psychology, among other areas, according to the kind of research, desired outcomes and data to be analyzed.

Another aspect to be aware is related to the interaction design (e.g., user interface design, usability, ergonomics etc.), specially regarding the usability, which refers to the ease of access and use of a product which is, in this case, the virtual reality environment. The patient should not have any bad experience or any technical difficulties while doing the task in the virtual environment. He or she does not have to learn how to use the VR system, but the patient may understand naturally how to handle virtual objects, comprise he is in a virtual environment and he can control and explore its features with no difficult. If the individual has any problem while using the VR system or finds it hard to use, it certainly it will compromises the researche's outcomes. 
Furthermore, it should be mentioned that, in most cases, both regarding to the cognitive development and the motor coordination development, it is a very time-consuming process and it requires extreme dedication to patients. Oftentimes, even if there is some improvement outcomes that seem insignificant for the researches, for people with disabilities and for professionals like physiotherapists and pedagogues, the minimal improvement on the cognitive or motor skills is equally important and it reflects on the quality of life of those individuals.

Finally, we believe VR has great potential to be effective in the treatment of people with intellectual and multiple disabilities, as well as other kinds of impairments. Besides, further investigation into the use of virtual reality in the treatment of people with intellectual and multiple disabilities is needed given the possible benefits for those people. Also, it is important to considered that this is a multidisciplinary area which extends beyond computer science.

\section{Author Contributions}

- Rian Dutra da Cunha: Text writing and Literature review.

- Frâncila Weidt Neiva: Organization of the literature review protocol and text review.

- Rodrigo Luis de Souza da Silva: Research advisor.

\section{References}

[1] ORELOVE, F. P.; SOBSEY, D.; SILBERMAN, R. K. Educating children with multiple disabilities: A collaborative approach. 4. ed. Baltimore, USA: Paul H Brookes Pub Co, 2004. v. 1.

[2] TURNBULL, A. P. et al. Exceptional lives: Special education in today's schools. 3. ed. London,UK: Pearson, 1995. v. 1.

[3] KANNER, L. et al. Autistic disturbances of affective contact. Nervous Child, v. 2, n. 1, p. 217-250, 1943.

[4] MYERS, B. et al. Strategic directions in humancomputer interaction. ACM Computing Surveys (CSUR), v. 28, n. 4, p. 794-809, 1996.

[5] CROMBY, J.; STANDEN, P. J.; BROWN, D. J. The potentials of virtual environments in the education and training of people with learning disabilities. Journal of Intellectual Disability Research, v. 40, n. 6, p. 489-501, 1996.

[6] KITCHENHAM, B.; CHARTERS, S. Guidelines for performing Systematic Literature Reviews in Software Engineering. Keele, UK, 2007.

[7] COLBY, K. M. The rationale for computer-based treatment of language difficulties in nonspeaking autistic children. Journal of Autism and Developmental Disorders, v. 3, n. 3, p. 254-260, 1973.
[8] GOLDENBERG, E. P. Special technology for special children. 1. ed. [S.1.]: Baltimore: University Park Press, 1979. v. 1.

[9] BERNARDOPITZ, V.; ROOS, K.; BLESCH, G. Computer-assisted instruction in autistic-children. Zeitschrift Fur Kinder Und Jugendpsychiatrie Und Psychotherapie, v. 17, n. 3, p. 125-130, 1989.

[10] GEOFFRION, L. D.; GOLDENBERG, E. P. Computer-based exploratory learning systems for communication-handicapped children. The Journal of Special Education, v. 15, n. 3, p. 325-332, 1981.

[11] MCLELLAN, H. Virtual environments and situated learning. Multimedia Review, v. 2, n. 3, p. 30-37, 1991.

[12] DARROW, M. Virtual reality's increasing potential for meeting needs of persons with disabilities: What about cognitive impairments. Proceedings of the Third International Conference on Virtual Reality and Persons with Disabilities, v. 1, n. 1, p. $40-41,1995$.

[13] STANDEN, P. J.; LOW, H. L. Do virtual environments promote self-directed activity? a study of students with severe learning difficulties learning makaton sign language. In: SHARKEY, P. (Ed.). Proceedings of the First European Conference on Disability, Virtual Reality and Associated Technologies. Reading, UK: The University of Reading, 1996. v. 1.

[14] CROMBY, J.; STANDEN, P. J.; BROWN, D. J. The potentials of virtual environments in the education and training of people with learning disabilities. Journal of Intellectual Disability Research, v. 40, n. 6, p. 489-501, 1996.

[15] STRICKLAND, D. Virtual reality for the treatment of autism. Studies in health technology and informatics, v. 44, n. 1, p. 81-86, 1997.

[16] LATASH, M. L. Virtual reality: a fascinating tool for motor rehabilitation (to be used with caution). Disability and Rehabilitation, v. 20, n. 3, p. 104-105, 1998.

[17] SCHULTHEIS, M. T.; RIZZO, A. A. The application of virtual reality technology in rehabilitation. Rehabilitation psychology, v. 46, n. 3, p. 296, 2001.

[18] BROOKS, B. et al. An evaluation of the efficacy of training people with learning disabilities in a virtual environment. Disability and rehabilitation, v. 24, n. 11-12, p. 622-626, 2002.

[19] BOZGEYIKLI, L. et al. Vr4vr: Towards vocational rehabilitation of individuals with disabilities in immersive virtual reality environments. In: QUARLES, J.; LANGE, B. (Ed.). Virtual and Augmented Assistive Technology (VAAT), 2014 2nd Workshop on. Piscataway,USA: IEEE, 2014. v. 1.

[20] BRUCKHEIMER, A. D.; HOUNSELL, M. da S.; SOARES, A. V. Dance2rehab3d: A 3d virtual rehabilitation game. In: TREVISAN, D. G.; COSTA, R. M. E. da (Ed.). 14th Symposium on Virtual and Augmented Reality (SVR). Niterói, Brazil: IEEE, 2012. v. 1. 
[21] ANDERSON, F.; ANNETT, M.; BISCHOF, W. F. Lean on wii: physical rehabilitation with virtual reality wii peripherals. Stud Health Technol Inform, v. 154, n. 154, p. 229-34, 2010.

[22] PETTICREW, M.; ROBERTS, H. Systematic reviews in the social sciences: A practical guide. 1. ed. Hoboken, USA: John Wiley \& Sons, 2008.

\section{Appendix}

[A1] Amaral, C. P., Simões, M. A., Mouga, S., Andrade, J., And Castelo-Branco, M. A novel brain computer interface for classification of social joint attention in autism and comparison of 3 experimental setups: A feasibility study. Journal of Neuroscience Methods 290, 1 (2017), 105-115.

[A2] Bai, Z., Blackwell, A. F., And Coulouris, G. Using augmented reality to elicit pretend play for children with autism. IEEE transactions on visualization and computer graphics 21, 5 (2015), 598-610.

[A3] Bekele, E., Crittendon, J., Zheng, Z., Swanson, A., Weitlauf, A., Warren, Z., AND SARKAR, N. Assessing the utility of a virtual environment for enhancing facial affect recognition in adolescents with autism. Journal of autism and developmental disorders 44, 7 (2014), 1641-1650.

[A4] Bian, D., Wade, J. W., SARKar, N., AND SWANSON, A. Physiology-based affect recognition during driving in virtual environment for autism intervention, 2 2015.

[A5] Cai, Y., Chia, N. K., Thalmann, D., Kee, N. K., Zheng, J., And Thalmann, N. M. Design and development of a virtual dolphinarium for children with autism. IEEE transactions on neural systems and rehabilitation engineering 21, 2 (2013), 208-217.

[A6] Chen, C.-H., LeE, I.-J., AND LiN, L.-Y. Augmented reality-based video-modeling storybook of nonverbal facial cues for children with autism spectrum disorder to improve their perceptions and judgments of facial expressions and emotions. Computers in Human Behavior 55, 1 (2016), 477-485.

[A7] Chung, P. J., VAnderbilt, D. L., AND SoAres, N. S. Social behaviors and active videogame play in children with autism spectrum disorder. Games for health journal 4, 3 (2015), 225-234.

[A8] DA Silva, C. A., Fernandes, A. R., And Grohmann, A. P. Star: Speech therapy with augmented reality for children with autism spectrum disorders. In International Conference on Enterprise Information Systems (Lisbon, Portugal, 4 2014), J. Cordeiro, S. Hammoudi, L. Maciaszek, O. Camp, and J. Filipe, Eds., vol. 1, Springer.
[A9] Fengfeng, K., And Sungwoong, L. Virtual reality based collaborative design by children with high-functioning autism: design-based flexibility, identity, and norm construction. Interactive Learning Environments 24, 7 (2016), 1511-1533.

[A10] FEngfeng, K., AND TAMI, I. Virtual-reality-based social interaction training for children with high-functioning autism. The Journal of Educational Research 106, 6 (2013), 441-461.

[A11] Fengfeng, K., Tami, I., Xinrong, X., Xinhao, X., NamuU, K., And Sungwoong, L. Experience of adult facilitators in a virtual-reality-based social interaction program for children with autism. The Journal of Special Education 48, 4 (2015), 290-300.

[A12] Gillespie-LynCH, K., Goldstein, G., ET Al. Connecting through kinect: Designing and evaluating a collaborative game with and for autistic individuals. In International Conference of Design, User Experience, and Usability (Vancouver, Canada, 7 2017), vol. 1 of Lecture Notes in Computer Science vol. 10290, Springer.

[A13] Herrera, G., Alcantud, F., Jordan, R., Blanquer, A., Labajo, G., and De Pablo, C. Development of symbolic play through the use of virtual reality tools in children with autistic spectrum disorders: Two case studies. Autism 12, 2 (2008), 143-157.

[A14] JiAnG, X., Hu, Z., AND WANG, W. Research on the rehabilitation of autistic children based on virtual motion system. In Information Technology in Medicine and Education (ITME), 2016 8th International Conference on (Fuzhou, China, 12 2016), S. Li, Ed., vol. 1, IEEE.

[A15] Kandalaft, M. R., Didehbani, N., KraWCZYK, D. C., Allen, T. T., And Chapman, S. B. Virtual reality social cognition training for young adults with high-functioning autism. Journal of autism and developmental disorders 43, 1 (2013), 34-44.

[A16] Kuriakose, S., ET AL. A step towards virtual reality based social communication for children with autism. In International Conference on Control, Automation, Robotics and Embedded Systems (CARE) (Jabalpur, India, 12 2013), J. Singh, Ed., vol. 1, IEEE.

[A17] KURIAKOSE, S., AND LAHIRI, U. Understanding the psycho-physiological implications of interaction with a virtual reality-based system in adolescents with autism: A feasibility study. IEEE Transactions on Neural Systems and Rehabilitation Engineering 23, 4 (2015), 665-675.

[A18] Lahiri, U., BeKele, E., Dohrmann, E., WARREN, Z., AND SARKAR, N. Design of a virtual reality based adaptive response technology for children with autism. IEEE Transactions on Neural Systems and Rehabilitation Engineering 21, 1 (2013), 55-64.

[A19] Lahiri, U., BeKele, E., Dohrmann, E., WARREN, Z., AND SARKAR, N. A physiologically informed 
virtual reality based social communication system for individuals with autism. Journal of autism and developmental disorders 45, 4 (2015), 919-931.

[A20] Lorenzo, G., Lledó, A., Pomares, J., And ROIG, R. Design and application of an immersive virtual reality system to enhance emotional skills for children with autism spectrum disorders. Computers \& Education 98, 3 (2016), 192-205.

[A21] Lotan, M., Yalon-Chamovitz, S., AND Weiss, P. L. T. Virtual reality as means to improve physical fitness of individuals at a severe level of intellectual and developmental disability. Research in developmental disabilities 31, 4 (2010), 869-874.

[A22] PARSONS, S. Learning to work together: designing a multi-user virtual reality game for social collaboration and perspective-taking for children with autism. International Journal of Child-Computer Interaction 6, 1 (2015), 28-38.

[A23] Parsons, S., Mitchell, P., And LeOnard, A. The use and understanding of virtual environments by adolescents with autistic spectrum disorders. Journal of Autism and Developmental disorders 34, 4 (2004), 449-466.
[A24] RAMACHANDIRAN, C. R., JOMHARI, N., THIYAGARAJA, S., AND MAHMUD, M. M. Virtual reality based behavioural learning for autistic children. The Electronic Journal of e-Learning 13, 5 (2015), 357-365.

[A25] Smith, M. J., Ginger, E. J., Wright, K., Wright, M. A., TAYlor, J. L., Humm, L. B., Olsen, D. E., Bell, M. D., And Fleming, M. F. Virtual reality job interview training in adults with autism spectrum disorder. Journal of Autism and Developmental Disorders 44, 10 (2014), 2450-2463.

[A26] STRICKLAND, D. A virtual reality application with autistic children. Presence: Teleoperators \& Virtual Environments 5, 3 (1996), 319-329.

[A27] Walker, Z., VAsquez, E., AND Wienke, W. The impact of simulated interviews for individuals with intellectual disability. Educational Technology \& Society 19, 1 (2016), 76-88.

[A28] WANG, M., AND REID, D. Using the virtual reality-cognitive rehabilitation approach to improve contextual processing in children with autism. The Scientific World Journal 2013, 1 (2013), 1-9. 